\title{
EL ESTADO DEL "CAPITALISMO DE SERVICIO PÚBLICO” ANTE LA PANDEMIA
}

Carlos Ruiz Encina y Sebastián Caviedes Hamuy 


\section{CARLOS RUIZ ENCINA}

Sociólogo y Doctor en Estudios Latinoamericanos.

Profesor Asociado en el Departamento de Sociología de la Universidad de Chile. Es presidente de la Fundación Nodo XXI.

\section{SEBASTIÁN CAVIEDES HAMUY}

Sociólogo y Magíster en Estudios Latinoamericanos. Profesor en el Programa Académico de Bachillerato y en la Facultad de Ciencias Sociales de la Universidad de Chile. Es investigador en sociedad y economía de la Fundación Nodo XXI. 


\section{EL ESTADO DEL “CAPITALISMO DE SERVICIO PÚBLICO” ANTE LA PANDEMIA}

\section{LA PROBLEMÁTICA ARTICULACIÓN ENTRE VIDA Y ECONOMÍA}

Si hasta inicios de marzo los ecos de la revuelta de octubre, con su crisis de dominación a cuestas, enfilaban el proceso político chileno hacia un escenario constituyente inédito por su naturaleza democrática y su composición paritaria, con la irrupción de la pandemia del Coronavirus han debido ser reorientados los esfuerzos personales y colectivos en favor de la protección de la vida y su cuidado. De este modo, Chile se ha sumado a una lucha de alcance mundial y que ha devuelto a la humanidad a épocas que, si bien se sabían no superadas, al menos se pensaba podían ser controladas de mejor manera con los progresos de la ciencia y la medicina.

Una idea ingenua por sí sola, como se ha visto, no solo por la mortandad provocada por el virus en todo el orbe, equivalente a la de cualquier conflicto bélico moderno, sino por cómo en la morigeración o amplificación de tal daño inciden la actitud y actuación de los gobiernos, así como la fortaleza del vínculo entre Estado y sociedad. En efecto, en el contexto de la mayor catástrofe sanitaria en más de un siglo, y cuando se alcanza una interconexión global única en la historia, la pandemia ilumina cada una de las fragilidades de la organización sanitaria y expone las reales prioridades de los países. Asimismo, evidencia la debilidad del sistema de cooperación internacional, por cuanto la búsqueda de insumos médicos, ventiladores mecánicos y de una vacuna que detenga la expansión de la enfermedad se ha convertido en una carrera individual orientada a monopolizar y mercantilizar la producción, distribución y uso de estos elementos.

Pero además de los problemas de salud, la pandemia también genera efectos devastadores en las economías, en particular, debido a las medidas de aislamiento social que han debido impulsar los gobiernos para contralar el contagio. La brusca detención de industrias, comercios y servicios, la quiebra de los stocks de oferta, la neutralización del consumo y la contracción de la liquidez monetaria han generado un impacto que horada ampliamente el tejido empresarial y los empleos, anticipando lo que se espera sea una nueva y gran crisis económica.

En las proyecciones conocidas a la fecha, a los avisos de recesión mundial pronosticados por el Fondo Monetario Internacional (FMI) y el Banco Mundial se suma la advertencia de la Organización Internacional del Trabajo (OIT), que señala que el desempleo mundial podría subir en hasta 24,7 millones de personas 
que se sumarían a los 188 millones actuales (OIT, 2020). Una cifra que revela una precariedad mayor si se tiene en cuenta que no se trata solamente de la cantidad de empleos (esto es, desempleo y subempleo), sino también de su calidad (léase salarios y acceso a protección social) y efectos en grupos más vulnerables.

Para nuestro continente, la Comisión Económica para América Latina y el Caribe (Cepal) prevé que el mayor impacto de la crisis económica recaerá sobre las pequeñas y medianas empresas y los trabajadores precarios e informales. Con ello, proyecta un incremento de la pobreza en América Latina de 185,9 a 219,1 millones de personas, y un aumento de la extrema pobreza de 67,5 a 90,7 millones (Cepal, 2020). A esto se suma la debilidad de los sistemas de salud de la región, poco integrados, de desigual acceso y con escasa infraestructura e insumos, así como el escenario de inestabilidad social y política que en varios países dominaba desde antes de la pandemia.

En Chile, por su parte, las primeras medidas gubernamentales llevadas adelante en los meses de marzo y abril (cuarentenas dinámicas, toques de queda y paralización focalizada de comercios), sin que se registraran aún los efectos más duros de la pandemia, impulsan desde ya incrementos en el desempleo, la informalidad y la pobreza ${ }^{1}$, así como un aumento en los procesos de quiebra de personas y empresas ${ }^{2}$. La tasa de desempleo del trimestre móvil febrero-abril llega al 9 por ciento (INE, 2020), pero sin que aún se contabilicen todos los despidos atribuibles a la crisis sanitaria, expresa, más bien, una mezcla de deterioros económicos previos relacionados con el agotamiento estructural del modelo económico chileno y la paralización de algunas actividades en los momentos más álgidos del estallido de octubre de $2019^{3}$.

1. Se proyecta que, a mediados de año, alrededor de un 18 por ciento de la fuerza laboral se encuentre en situación de no estar trabajando - entre 1,7 y dos millones de personas-, incluyendo a despedidos, suspendidos y desocupados (Alonso, 2020a).

2. Según el último informe de la Superintendencia de Insolvencia y Reemprendimiento, para el periodo enero-abril de 2020, los procesos de liquidación o quiebras de empresas suben un 11,5 por ciento, mientras los de personas lo hacen en un 20 por ciento. No obstante, cuando se mira la variación anual para el mes de abril, la crecida llega al 40 por ciento, la mayor cifra desde que existe esta figura legal (Alonso, 2020b).

3. Los datos del INE muestran también que se reduce en casi 700 mil personas la fuerza de trabajo respecto del trimestre móvil previo, pasando la mayoría de esos empleos perdidos a la categoría de inactivos. Se trata de personas que temporalmente dejaron de buscar trabajo, situación que, dependiendo del manejo de la crisis, puede convertirse en condición permanente. A ello se suma la brusca caída del empleo femenino, cuyo desempleo se eleva de 9,7 por ciento a 9,9 por ciento, mientras baja su tasa de participación de 52,1 por ciento a 47,3 por ciento, retrocediendo a tasas similares a las del año 2010 . 
Con todo, de esta preocupación inicial se escala a la que rodea el inevitable cambio en la composición social de la pandemia, que transita desde la zona oriente de Santiago - su localización inicial- a las comunas del sur y norponiente de la capital, así como desde zonas regionales acotadas a las capitales con mayores contrastes sociales y económicos internos. Esto es lo que se registra a partir del mes de mayo en Chile, ad-portas del invierno, con una crecida acelerada de los contagios y fallecidos diarios que amenaza con colapsar la atención médica de urgencia. Algo que obliga al gobierno a variar su estrategia inicial, que incluso lo había llevado a impulsar el regreso a una "nueva normalidad" a mediados de abril y a adoptar cuarentenas totales en zonas cada vez más extensas, en un formato que recuerda el estado de crisis social en que desembarcara el virus, con un alto contingente de vigilancia militarizada que ha puesto en alerta a observadores y organismos de derechos humanos.

Este agravamiento de la situación sanitaria del país, veloz como lo es el ritmo de contagio de la enfermedad, ha puesto a la sociedad ante un desafío ya advertido por otros países afectados por la pandemia: el de articular vida y economía, esto es, el respeto al aislamiento social y la supervivencia económica, especialmente entre la población más pobre o en situaciones económicas más inestables. Si bien es cierto que el virus no conoce fronteras ni distingue entre grupos sociales al momento de atacar, también lo es que la precariedad de las condiciones económicas y sociales de la vida cotidiana limita las posibilidades de enfrentar la enfermedad allí donde lo que imperan son frágiles economías familiares, altos niveles de endeudamiento y experiencias de hacinamiento. Una cuestión especialmente sensible en un país como Chile, marcado por la desigualdad y por una gran concentración económica, así como por el deterioro de servicios públicos que se encuentran extensamente privatizados, tal como lo dejara en claro el malestar transversal detonado antes del arribo del Coronavirus.

Al no bastar los mecanismos de mercado para salvar vidas en esta coyuntura, no solo por la ausencia de tal interés en la racionalidad orientada al lucro, sino sobre todo por el deterioro económico que crece, tal desafío exige ser enfrentado con una alta dosis de planificación estatal o, al menos, con intervenciones abiertas de los Estados con vistas a construir seguridades económicas que permitan a sus sociedades sobrellevar el confinamiento. La urgencia, en ese sentido, es lograr que el resguardo de la vida deje de ser un lujo entre la población más vulnerable, especialmente entre aquella que depende de ingresos diarios o semanales, trabaja en condiciones de alta desprotección laboral o vive en una crónica inestabilidad económica. El mundo popular, como se sabe, prácticamente no disfruta de un salario normal, recibido periódicamente, pues allí lo que impera son hogares con una altísima rotación de ingresos. 
Evitar que vida y economía se transformen en una encrucijada, especialmente para tales sectores sociales, implica un despliegue profundo de la acción y capacidades estatales en una dirección de mayor integración social y económica. Significa fortalecer sus capacidades de lucha por la vida y, con ello, las de toda la sociedad, en lugar de apuntalar los patrones hoy vigentes de acumulación de la riqueza, consabidamente excluyentes, que marcan la trayectoria reciente del país hasta la explosión social de hace unos meses. Sin el apoyo a estas familias no es posible el cumplimiento de las medidas sanitarias, lo que tiene un efecto para el conjunto de la sociedad. Esa es la ecuación vital.

Prospectivamente, además, el reto es moderar la destrucción económica que se avecina, evitando que el shock sanitario transforme la desestructuración productiva y financiera temporal en una condición permanente de la economía chilena, atendiendo a que la ola de crisis en el mundo muy probablemente será un hecho ineludible. En ese sentido, mirar la situación actual con un interés enfocado también en la superación de las limitaciones e ideologismos con que la crisis se enfrenta, pensando además en el lugar de Chile en el mundo tras esta pandemia, es válido para completar la comprensión de este proceso.

\section{POLÍTICAS SOCIALES EN UN ESTADO "AMPUTADO" DE BRAZOS: EL CASO DE LA BANCARIZACIÓN PRIVADA DEL GASTO SOCIAL DE EMERGENCIA}

Aunque de modo disímil, en todo el mundo los Estados han actuado para morigerar los efectos sanitarios y económico-sociales de la pandemia. En Asia, Europa y América Latina, además de las medidas de aislamiento social y de fortalecimiento de los sistemas de salud, gobiernos de todo signo adoptan medidas como la suspensión del pago de consumos básicos e impuestos, la prorrogación de deudas hipotecarias y de préstamos a la pequeña y mediana empresa o la ampliación en los plazos de los arriendos. Incluso en lugares como Holanda o Alemania se abren discusiones acerca del papel del Estado en la economía, más allá de su mera regulación, como lo ejemplifica el ingreso del gobierno alemán al control del 20 por ciento de la propiedad de Lufthansa tras la solicitud de un rescate económico por parte de esta aerolínea (Müller, 2020).

En el caso de Chile, además de acciones sanitarias orientadas a aumentar la cantidad de camas críticas, las pruebas de diagnóstico y el número de especialistas en la red pública y privada, el confinamiento ha sido acompañado, desde que se declarara la crisis, por medidas económicas de emergencia destinadas al apoyo tanto de las empresas como del empleo y las familias. 
En el caso del soporte a las empresas, a la implementación inicial de una serie de medidas de carácter administrativo y tributario durante marzo se ha sumado a partir del mes de mayo un segundo paquete de iniciativas económicas que considera un amplio plan de garantías crediticias. En este último caso, el apoyo se ha materializado a través del Fondo de Garantía de Pequeños Empresarios (Fogape), cuyo patrimonio ha sido incrementado en alrededor de US\$3.000 millones. Con esta medida, presentada inicialmente como un fondo con potencialidad de llegar a cerca de un millón de empresas, fundamentalmente micro, pequeñas y medianas (MiPymes), se ha buscado proveerles financiamiento para cubrir necesidades de capital de trabajo, lo que evita la ruptura de las cadenas de pagos y las quiebras. Entregando el fondo recursos por hasta un monto equivalente al 25 por ciento de las ventas anuales de las empresas elegibles, y aumentando además las garantías actuales hasta un máximo de 85 por ciento del monto del crédito, la iniciativa fija una cobertura decreciente según el tamaño de las empresas, en rangos que van desde el 85 por ciento de garantía del Estado para empresas con ventas inferiores a 25 mil UF anuales hasta un 60 por ciento para aquellas con ventas entre 600 mil UF y un millón de UF, es decir, grandes empresas (Ministerio de Hacienda, 2020).

A falta de un banco de desarrollo o, más bien, producto de la negativa gubernamental a capitalizar y recurrir al BancoEstado de ese modo, dichos recursos han sido canalizados a través de la banca privada. Concretamente, 11 instituciones se han adjudicado la licitación del monto de garantías estatales ${ }^{4}$ bajo la justificación de su mayor eficacia para cubrir el amplio espectro empresarial al que se apunta. Adicionalmente, la ley contempla que los bancos participantes posterguen cuotas o vencimientos de las deudas preexistentes a las empresas que ya son sus clientes, para asegurar que esta inyección de recursos entregue dinero fresco a la economía.

Transcurridas algunas semanas desde la puesta en marcha de esta medida, y varios miles de créditos aprobados después, el resultado ha sido el alegato de las principales asociaciones de MiPymes respecto al magro alcance efectivo del proceso, la falta de respuesta a las empresas que buscan acogerse y los bajos montos entregados por las entidades bancarias. A esto se suman los incentivos para que las empresas más necesitadas desistan de optar a estos créditos, presentes en la ley desde un inicio: las empresas deben garantizar por su cuenta a lo menos un 15 por ciento de lo que les presten, aunque en un valor siempre superior por cada peso que el banco les entregue en crédito no garantizado por el Estado. Además, son

4. Incluye a los bancos Internacional, Estado, BCI, Itaú-Corpbanca, Bice, Santander, Security, Consorcio, de Chile y Coopeuch (El Mostrador, 2020). 
automáticamente excluidas empresas que mantengan cualquier crédito pendiente solicitado con anterioridad.

En respuesta a los reclamos, tanto el ministro de Hacienda como el presidente de la Asociación de Bancos e Instituciones Financieras han reducido las expectativas respecto al alcance de la medida. En particular, el gremio bancario ha indicado que el universo elegible por sus socios no superaría las 600 mil empresas. Del mismo modo, su representante ha señalado que los bancos no tienen responsabilidades con las empresas no bancarizadas (ADN Radio, 2020), lo que en la práctica significa el grueso de las MiPymes, pues menos del 50 por ciento de ellas usa el crédito bancario como fuente de financiamiento, por lo que prevalecen fuentes informales, casas comerciales y financiamiento estatal (Ministerio de Economía, 2019).

Lo anterior constituye un desenlace que no debiese extrañar, considerando que, a poco de iniciado el proceso, el gobierno debió formular un reglamento para obligar a que al menos el 25 por ciento del fondo fuera a parar a las empresas de menor tamaño (Leiva, 2020). Ello, tras un escenario postlicitación marcado por los bajos montos solicitados por los bancos para los tramos relacionados con empresas más pequeñas, incluso en el caso de entidades como el BancoEstado, cuya dimensión en el mercado bancario y llegada a este segmento no tiene paragón con el resto (El Mostrador, 2020).

El fracaso de una ayuda estatal a las MiPymes anclada en los bancos privados es el fracaso de la ortodoxia neoliberal y del instinto de captura empresarial de la acción estatal. Este se relaciona con el poder que les otorga el Estado a estas instituciones para dirimir, en medio de una crisis vital, sobre quienes pueden o no acceder a los recursos fiscales ofrecidos. $\mathrm{Y}$ es que, como los banqueros arguyen, al no existir un 100 por ciento de aval estatal y, por tanto, compartirse parte de los riesgos en la entrega de los créditos, no sería posible llegar a las empresas potencialmente menos solventes, que son generalmente las más pequeñas. A su juicio, el paquete de medidas apenas constituiría una distribución de crédito y no un subsidio ni un bono para las empresas solicitantes, por lo que los bancos no deben operar como una "ventanilla" del Estado (ADN Radio, 2020).

Pero sí se trata de un subsidio estatal a la acumulación privada de tales bancos, debido a que la medida les asegura un lucro, a todo evento, por un porcentaje siempre superior a al menos la mitad del crédito otorgado. Algo que las mismas entidades refuerzan al concentrar sus esfuerzos en las empresas de mayor tamaño debido a la diferencia en los volúmenes de recursos que ellas solicitan en comparación con las empresas más pequeñas. Se trata, además, de un lucrativo negocio por el alto flujo de nuevos clientes que tocarán sus puertas al agigantarse el drama de la destrucción económica provocada por la pandemia. Ello, por otro lado, en un escenario de crisis en que crece y no se contrae — como en otras crisis económicas- 
el crédito comercial (Banco Central, 2020a) debido a fórmulas de bancarización forzada como esta, en lo que es una tendencia que advierte sobre la ambición del capital financiero desanclado de la depresión del sector productivo, aunque siempre dependiente de aquel.

Las críticas que suscita la parcialidad de esta política de ayuda a las empresas, que margina, en los hechos, a una parte considerable del tejido empresarial más pequeño del cual depende la gran mayoría de los empleos en Chile, lleva al gobierno, a través de la Corporación de Fomento de la Producción (Corfo), a proponer alternativamente la creación de una Red de Instituciones No Bancarias para solventar la demanda por recursos que ha quedado pendiente. En efecto, y aunque aún se trata de un proyecto de ley que será llevado al Congreso, se propone la creación de un fondo que permitiría garantizar créditos dirigidos a 40 mil MiPymes. Siguiendo una lógica similar a la utilizada con el Fogape, dicho fondo, con un monto de garantía estatal por US $\$ 150$ millones, espera recaudar recursos por US\$1.000 millones a partir de una licitación orientada a las Administradoras Generales de Fondos, esto es, AFP, compañías de seguros, fondos de inversión e inversionistas privados. Luego, con aquel fondo constituido, un amplio espectro de intermediarios empresariales no bancarios - factoring, leasing, fondos de inversión pública, cajas de compensación y cooperativas - se haría cargo de realizar préstamos directos a las MiPymes a una tasa de interés no fijada por el Ejecutivo sino por la propia industria, apelando a la competencia del mercado (Diario Financiero, 2020a).

A la espera de concretarse este segundo plan de garantías crediticias, esta vez encabezado por instituciones no bancarias, es posible advertir que, así como es diferenciada la estructura de beneficiarios de estas políticas de emergencia, lo es también la estructura de actores económicos favorecidos para participar en tales procesos y de las subvenciones estatales que tales políticas entregan. Y es que, si bien en todos los casos se trata de recursos fiscales, lo que los dinamiza y apalanca son sectores sociales y agentes económicos distintos. Por eso, si a la banca privada no le interesa dinamizar sino a las grandes empresas y MiPymes de mayor cuantía (en buena medida, quienes son sus clientes habituales), ante la mantención del problema de falta de liquidez entre las empresas de menor tamaño - que a esta altura ya ha significado la liquidación de muchos pequeños comercios- se abre la puerta a las instituciones no bancarias que esperan su turno en el reparto de los recursos estatales utilizados para aplacar la crisis. Más aún, en este caso, la complementariedad de ambas iniciativas significa abrir el camino a los dos grandes pilares del sistema financiero chileno: la banca privada y las administradoras de fondos generales.

Con todo, más grave que el lucro con estas medidas de emergencia es la renuncia del Estado a su responsabilidad social en favor de las definiciones del interés 
particular. Peor aún, la definición gubernamental de dejar en manos de actores económicos privados la implementación, gestión y administración de importantes políticas sociales en medio de una crisis vital proyecta la sombra de un Estado "amputado", uno que decide usar brazos privados para ejecutar las políticas de emergencia.

Pero la revelación de un Estado constreñido, sin fuerzas ni herramientas, se vislumbra también en la incapacidad de este último para definir y hacer cumplir lineamientos generales sobre los cuales deba orientarse la acción de las empresas y los empresarios, lo que permitiría un marco de regulación general de las relaciones de este actor con el resto de la sociedad.

Esto queda en evidencia en el caso de las otras dos iniciativas económico-sociales desplegadas por el gobierno durante la coyuntura sanitaria, esta vez orientadas al apoyo del empleo y las familias. En el primer caso, la Ley de Protección del Empleo, que ha permitido a las empresas congelar los contratos de sus empleados y traspasar el cargo de sus salarios a los ahorros individuales del fondo del seguro de cesantía, en una especie de "préstamo" del trabajo al capital sin fecha de devolución, ha sido utilizada sin tapujos también por grandes empresas, pese a que la ley, originalmente, como ocurriera con las garantías crediticias, estaba dirigida a las MiPymes. Esto ha sido posible por el principio de "buena fe" que cruza a la legislación, sin fiscalización respecto de si las empresas están en condiciones deterioradas o en riesgo de detener sus operaciones (Urquieta, 2020), lo que confirma la ya arraigada política neoliberal de prescindencia del Estado en la regulación de las relaciones laborales en un país donde, además, los sindicatos son débiles.

Mientras en países europeos y otros tantos del propio mundo capitalista desarrollado corren con urgencia medidas de financiamiento y asignaciones directas sin mediaciones empresariales de ningún tipo, mientras además en influyentes medios circulan discusiones sobre la necesidad de reconstruir los servicios públicos, hacer más seguros los mercados laborales o mejorar la redistribución del ingreso tras la tragedia vivida con la pandemia ${ }^{5}$, lo que marca el curso chileno son políticas que no logran desapegarse del libreto de construir oportunidades de acumulación empresarial, directa o indirectamente. El Estado, para ello, renuncia a formas de ejecución y fuentes de financiamiento distintas a las que signifiquen algún beneficio para los distintos segmentos del empresariado, al punto de conjugarse un escenario en el que parece priorizarse el acceso equitativo a los beneficios económicos que potencialmente podría producir esta crisis mientras la mayoría de los costos son

5. Es lo que planteara el periódico británico Financial Times (2020) en su editorial del pasado 3 de abril. 
reservados para el resto de la sociedad, en una escala de creciente urgencia entre los más pobres y vulnerables.

Sin ir más lejos, la única política de urgencia directamente basada en transferencias directas del Estado (y que completa el cuadro de medidas desarrolladas hasta ahora), el Ingreso Familiar de Emergencia, muestra una insuficiencia tal para cubrir las necesidades básicas de la población — no resguardando ni la situación económica ni sanitaria- que ha debido ser acompañada de la entrega de cajas de mercadería que, además de erigirse como una medida parcial y organizarse con un sinnúmero de dificultades, corre el riesgo de destruir los pequeños comercios colindantes a los barrios y poblaciones en que las canastas serán entregadas, a la vez que constituye otro subsidio empresarial para algunas grandes empresas distribuidoras y supermercadistas.

La orientación social y económica que muestran las políticas de emergencia no es creación original del gobierno, sino continuación de una fórmula que está en el trasfondo de la explosión social que se produjera en octubre: el "capitalismo de servicio público" que distingue al modelo económico chileno. En efecto, en casi cinco décadas de neoliberalismo, lo que profundiza la colonización mercantil de la vida cotidiana es el funcionamiento de una infraestructura de acumulación empresarial con dependencia del Estado, cuyo rasgo característico es su alto beneficio privado y gran costo fiscal. Iniciada en dictadura con la privatización de los servicios sociales, tras una primera oleada privatizadora enfocada en las antiguas empresas estatales, lo que sigue en democracia es la profundización de una dinámica en la que, a través de un cúmulo de bonos, subsidios, licitaciones y marcos regulatorios específicos, el Estado estimula el crecimiento de grandes empresas privadas que ocupan el espacio de la provisión de servicios públicos al que el Estado renuncia al privatizarlos.

De esta manera, e influenciada por el pregón monetarista de la "oferta a la demanda" o voucher, durante estas décadas recientes se erige una intrincada red de propietarios, inversionistas y concesionarios en rubros que exceden las áreas primigenias de la salud, educación, pensiones y vivienda, para ampliarse a las carreteras y autopistas, puertos y aeropuertos e incluso a las cárceles concesionadas e instituciones de acogida de la niñez pobre.

Es la paradoja de una mercantilización cada vez más amplia de la vida social, en la que en muchos casos dichos mercados no funcionan como tales, esto es, en la forma esperada de emprendimiento e inversión bajo condiciones de riesgo empresarial, típicamente capitalista, y se abre, por el contrario, una serie de nichos de acumulación regulados y mantenidos con recursos fiscales.

Se trata, en definitiva, de una determinación política, no mercantil, de las condiciones de acumulación, que redunda en una producción política de la desigualdad más que del mercado reiteradamente invocado en los ideologismos 
al uso $^{6}$. Se trata de una cuestión que explica la tendencia a la oligopolización en prácticamente todos los mercados de servicios sociales y básicos en Chile, pues, como lo ejemplifica la bancarización de la ayuda estatal a las MiPymes, aunque esta vez al alero de un gasto social que es de emergencia, las diferencias también subyacen dentro del propio empresariado criollo. Asimismo, releva la importancia del Estado para el desarrollo del neoliberalismo chileno, pese a los discursos sobre el "Estado mínimo" y las diatribas contra este con los que se ha querido enmascarar el carácter político de esta concentración de patrimonio, riqueza y oportunidades (Ruiz, 2019).

Pero el rito de encauzar fondos sociales estatales a través de la banca privada no es nuevo. Ya hace unos años los gobiernos de la Concertación pusieron en marcha el Crédito con Aval del Estado en la educación superior, originando un nuevo problema social, la deuda educativa, que ha producido toda una generación de trabajadores endeudados. Efectivamente, el subsidio estatal a la ganancia a través de créditos a Pymes que canaliza la banca privada tiene antecedentes en la educación, la salud, vivienda y otras áreas de protección social derivadas a privados a través del gasto social estatal por varias décadas. Sin embargo, en este caso particular, la renuncia a ejecutar con brazos propios la política social, así como todo el circuito financiero que recorre la elección de unas fuentes de financiamiento sobre otras - por ejemplo, basadas en el endeudamiento del Estado chileno, como ha sido recomendado por varios expertos-, advierte de una nueva dimensión de este capitalismo de servicio público.

En fin, todo lo anterior, además de encontrarse en la médula de la revuelta de octubre y de todas las limitaciones que hoy se observan en cuanto al manejo de la crisis sanitaria y económico-social, alerta respecto a que las consecuencias de esta coyuntura, por más que se espera sean profundas, no tienen una dirección determinada. Por el contrario, dependen de las opciones políticas y sociales que se adopten y no de la veleidad de la pandemia.

\section{OPCIONES Y EFECTOS SOCIALES EN TIEMPOS DE PANDEMIA: ¿HACIA UN NUEVO PATRÓN DE DESIGUALDAD?}

Además de replicar los ideologismos, límites e intereses que han rodeado al neoliberalismo chileno en las últimas décadas, el carácter marcadamente empresarial mostrado por las políticas de emergencia del gobierno entraña el riesgo de que la forma en que se articule vida y economía en la actual coyuntura, lejos de aprontarse

6. Para ahondar en el concepto de "capitalismo de servicio público", véase Ruiz (2019). 
a construir condiciones sociales y económicas acordes a la premura del momento, acreciente los rumbos de la desigualdad, la concentración económica y la precariedad de la vida.

En primer lugar, porque la captura empresarial de las políticas de emergencia deja en manos de los empresarios y no de las empresas los subsidios estatales, alimentando con ello una concentración económica arrastrada desde hace décadas. En segundo término, porque también impide la universalización de las ayudas estatales, ya sea porque se deja en manos de intereses particulares la definición respecto a quiénes pueden acceder a estas como porque se permite una ganancia que poco dinamiza al conjunto de la economía, en tanto corresponde a un lucro rentista.

Así, en este último caso, y ya en condiciones de amenazante retroceso económico, el esfuerzo del gasto social estatal se diluye, impidiendo la lucha por la vida a economías familiares ya muy deprimidas, entre las que se cuentan pequeños comercios y trabajadores informales o por cuenta propia. Lo que sigue es la incapacidad de dar cumplimiento a las exigencias sanitarias. Chile detenta una informalidad laboral que bordea el 30 por ciento, con grandes mayorías que viven atadas a trabajos sin contrato ni previsión ni cotizaciones en la seguridad social o salarios estables, de ingresos diarios o por magros lapsos de tiempo. A su vez, gran parte de la población está endeudada. Una mezcla que debilita la capacidad de las economías más precarias para enfrentar la urgencia sanitaria.

Por otro lado, en la medida en que el salvataje a las empresas de todo tipo, pero especialmente a las MiPymes, no solo necesita de crédito sino de quienes compren sus productos, la promoción del consumo popular — demanda que expresa de manera más dramática la ecuación feroz de economía y vida- después de la pandemia y durante la crisis económica, en el contexto de una depresión de los ingresos generales y de un alto desempleo, será diferente si es que aquel es promovido vía transferencias directas a las personas, programas de empleo sustantivos o agudizando el crédito. Una opción, esta última, que, además de beneficiar potencialmente a las mismas instituciones no bancarias antes mencionadas, sobrecargaría un ítem, la deuda de hogares, ya extremo en el caso chileno ${ }^{7}$.

De todos modos, en la medida en que el problema sanitario persista y se extienda en el tiempo al no adoptarse medidas para el conjunto de la población, se agudizará la pauperización general de la sociedad. El deterioro económico y laboral podría ampliarse rápidamente hacia otros grupos sociales que, aunque hoy muestran estar

7. El Banco Central (2020b) advertía que durante el año pasado el endeudamiento escalaba a un 75 por ciento de los ingresos familiares en promedio. 
en mejor situación, también pueden ser alcanzados por la ola recesiva. Según la Organización para la Cooperación y el Desarrollo Económicos (Ocde) (2020), un 53 por ciento de los chilenos correría el riesgo de caer en la pobreza si tuviera que renunciar a tres meses de sus ingresos. De allí que no facilitar las condiciones de resistencia a la pandemia para el conjunto de la sociedad, sin exclusión, constituiría el fracaso del Estado neoliberal chileno.

Junto con ello, una ayuda parcial y no sustantiva del Estado a la población en general, sumada a la mediación empresarial, podría impulsar un cambio en los rasgos de la desigualdad en Chile. Hasta ahora, el patrón de desigualdad, originado en los años noventa a partir de la bonanza económica ligada al ciclo favorable que vivieran las materias primas y commodities - como el cobre- y la distribución disímil de estos dividendos, pese a la elevación general de los ingresos (Fazio y Parada, 2010; Ffrench-Davis, 2018), produjo un panorama social marcado por una aguda disminución de la pobreza y un alza continua en la concentración económica ${ }^{8}$. Ello permitió la divulgación de la imagen de Chile como un país con cuestiones de dignidad elemental ya resueltas, en contraste con sus pares latinoamericanos en permanentes crisis.

Sin embargo, si bien dicho patrón implicó dos curvas que se distanciaban, una de ellas, la de la concentración económica, siempre tendió a aumentar más velozmente que la de la disminución de la pobreza, lo que fue aumentando la polaridad entre ambas. Algo que, de hecho, incubó la molestia de los sectores medios, que también ha retratado el estallido social de octubre. Unos efectos sociales, por lo demás, típicos de los auges económicos abruptos y sustentados en los vaivenes de las materias primas, que suelen alentar el enriquecimiento y acaparamiento de las oportunidades en grupos minoritarios - los "ganadores" en dichos ciclos de éxito-que, a menudo, ya detentan el monopolio del poder y la riqueza desde antes (Ruiz y Caviedes, 2020).

Pero ahora la distancia apunta directamente hacia el aumento en ambas direcciones, pues la bancarización privada excluye a los sectores más pobres y eleva lucros en grupos más pudientes, mientras las restricciones a la universalidad en las medidas segmentan aún más a los grupos sociales en escenarios de crisis aguda como el que se vive. De este modo, los efectos socioeconómicos de la pandemia pueden hacer crecer tanto la desigualdad como la pobreza y la concentración de la riqueza. $\mathrm{O}$, lo que es lo mismo, pueden tender a distanciarse los dos polos: unos

8. Entre 1990 y 2009, las cifras de pobreza caen, aproximadamente, de un 39 por ciento a un 15 por ciento (Ffrench-Davis, 2018). Mientras tanto, la desigualdad de ingresos, medida por el índice Gini, no se reduce ni significativa ni automáticamente con el crecimiento económico (Solimano, 2012). 
ganan subsidios que alientan la concentración ${ }^{9}$ mientras otros, como no se veía hace tiempo, pueden hundirse y volver a la pobreza.

Se trata de fenómenos que no necesariamente ocurren a la vez en las sociedades, lo que implica que se trata de una polaridad que no tiene nada de natural. Por el contrario, dependen de las opciones sociales y económicas que guíen la aplicación de las medidas estatales de contingencia. Así las cosas, lo que se observa en Chile hoy es un tipo de acción gubernamental que contribuye a producir políticamente una nueva fisonomía de la desigualdad. Algo que no responde ni al mercado ni a la pandemia por sí solos, que no es producto de la "mano invisible" ni viene encadenado al virus.

Por su parte, la dilatación y parcialidad de las medidas de emergencia, junto con la ilegitimidad de una mediación empresarial cuestionada en un país que ha debido forzosamente desplazar una crisis social por otra, abren la posibilidad de una mutación también en el patrón de conflicto social. En lo inmediato, porque la escalada social es alimentada en la medida en que el confinamiento se transforma en una medida irrealizable para grupos cuya subsistencia depende de su exposición diaria en las calles. La interrupción del trabajo significa empobrecimiento, a la vez que aumento de los riesgos sanitarios. Así lo confirman las protestas que comienzan a abrirse paso en barrios populares de Santiago ante el fracaso de la imposición gubernamental de asignaciones familiares miserables, que traen a la palestra carencias como el hambre, que se creía superada en Chile.

No debe olvidarse que el origen de la revuelta de octubre es la crisis de las propias contradicciones sociales y culturales que modelaran a la sociedad chilena en su historia reciente. Es una rebelión de los hijos de la modernización neoliberal, cuya demanda por dignidad remite al gran abuso que se vive y percibe en la vida cotidiana (Ruiz, 2020). Por ello, mantenerse en la senda de un Estado que siga comprometiéndose solo con una parte de la sociedad y no con el conjunto es avivar el fulgor de un malestar que apenas ha quedado suspendido, pero no silenciado.

Si bien un aspecto central de la revuelta social es su carácter inorgánico, sin liderazgos a la cabeza, como una explosión de masa individual (Ruiz y Caviedes, 2020), ante la ineficacia de las medidas gubernamentales y la manipulación que de ellas se hace, la respuesta de base de la sociedad vuelve a producirse. Y es que, pese a situaciones atribuibles a años de individualismo agresivo o a azotes surgidos

9. La concentración económica puede ampliarse, además, con la expansión de las inversiones chilenas en América Latina. Como advierte la agencia Boston Consulting Group (Diario Financiero, 2020b), dependiendo de cómo salga el país de la crisis y, sobre todo, con qué tipo de medidas lo haga, una disponibilidad de liquidez de los grupos económicos locales podría permitirles salir a comprar a precios bajos en economías que probablemente estén deprimidas. 
de la descomposición social como el narcotráfico, lo que emerge en virtud de esa paradojal distancia física, que no hace sino reforzar el vínculo societario, es una nueva solidaridad. Una que, a pesar de haber aparecido inicialmente como preocupación familiar, de apoyo a los más cercanos, se proyecta luego en un incipiente fenómeno de organización comunitaria. En ello se incluyen cooperativas populares para la distribución de alimentos o recursos como el agua, la protección comunitaria de la salud con los esfuerzos de los trabajadores médicos de todo tipo o el apoyo en la gestión de los cuidados y contra el maltrato intrafamiliar en el marco del confinamiento obligado (Fundación Nodo XXI, 2020). A esto se suma la labor de universidades y asociaciones gremiales, así como el trabajo de algunas alcaldías y sus municipalidades, que se enfrentan a los designios y desidia gubernamentales.

Se mezclan, así, viejas formas de organización y resistencia popular con otras surgidas de la organicidad territorial heredada de octubre. Es la vuelta de las ollas comunes, pero unida a la más amplia dignidad que exige el nuevo pueblo que irrumpe en los últimos meses.

Ciertamente, la convergencia de las crisis en curso y las respuestas sociales que brotan en la emergencia no resuelven el asunto político que acompaña a la politización que puede estar resurgiendo. En el abismo entre política y sociedad que distingue a la crisis chilena, aún queda pendiente la cuestión de la mediación política. Sin ella, la crisis múltiple que parece erigirse marcará indeterminadamente el proceso constituyente que se avecina. La historia es muy clara respecto a que no hay una relación directa entre crisis y transformación. La forma en que dicha transformación se produzca requiere de esa mediación política.

Con todo, la pandemia y la restrictiva respuesta estatal frente a ella, bajo el influjo de este régimen del capitalismo de servicio público, desnudan la necesidad de cambios tanto en las orientaciones sociales del Estado como en sus funciones e instituciones.

\section{TRANSFORMACIÓN PRODUCTIVA Y DEMOCRATIZACIÓN DE LA INSTITUCIONALIDAD SOCIAL ESTATAL}

Las constricciones del capitalismo de servicio público que afloran en medio de la crisis sanitaria indican la necesidad de cambios constitucionales enfocados no solo en el sistema político, sino también en reformas estructurales e institucionales. Ello, porque estas últimas dimensiones sustentan los preceptos que resguardan y reproducen aquel régimen de acumulación capitalista, como versión extrema de la noción de subsidiariedad que preside la concepción de Estado amparada en la Constitución de 1980. 
La magnitud de la crisis económico-social que se asoma, en particular, repone el debate sobre la urgencia de una transformación productiva. Por un lado, como reforma sustantiva a un modelo de crecimiento basado en rentas de recursos naturales, de consabido carácter oligopólico, concentrador y excluyente, y que hoy ya no es capaz de proveer las tasas de crecimiento que detentara desde fines de los años ochenta y durante todos los noventa, fundamentalmente por la contracción del crecimiento y la productividad del trabajo. Pero, además, porque dependiendo del camino que siga la crisis, este puede ser un tiempo de reorganización del sistema económico, como ocurriera en los años ochenta. En efecto, a nivel del empresariado, "plata nueva" puede surgir mientras segmentos favorecidos en el ciclo económico anterior pueden quedar en el camino. Del mismo modo, podrían develarse tendencias de cambio en el trabajo y la forma de sociedad.

El retorno al desarrollo interno, en el marco de una reinserción de la economía chilena en el concierto mundial, ciertamente surge como opción interesante. Empero, tal apuesta no puede significar volver a viejas ensoñaciones con un proteccionismo como vía de promoción de un brote industrial ante una internacionalización económica que no existía en el siglo XX, cuando esas políticas tuvieron lugar. Esto obliga a pensar una mayor capacidad de fomento e innovación estatal, así como una mayor participación de la sociedad civil a través de cooperativas y otras formas comunitarias que exigen ampliar las formas de propiedad.

Por añadidura, a reformas de tipo económico deben sumarse otras de índole institucional si es que se quiere replantear seriamente el problema del crecimiento, desarrollo y de los derechos y la protección social en Chile. No solo se trata de la economía, sino también de las instituciones que la dirigen y las orientaciones prevalecientes en ellas. El ejemplo de la crisis sanitaria, sin ir más lejos, muestra que los enfoques ortodoxamente monetaristas o bien la carencia de brazos estatales para actuar en contextos como estos producen una dependencia impropia de la banca privada para discriminar sobre la aplicación de los fondos estatales de emergencia, lo que amplifica y agudiza los riesgos que hoy son vitales.

En sus trabajos sobre el papel del Estado en los procesos de desarrollo latinoamericanos, el sociólogo Enzo Faletto (1989) destacaba la necesidad de diferenciar entre la institucionalidad política y social del Estado a partir de la distinción entre su carácter y funciones. En concreto, porque la institucionalidad estatal no tiene que ver solamente con el sistema político — como a menudo parece advertir la politología - ni tampoco únicamente con funciones de fomento o de regulación económica. En vez de eso, y relacionado con lo estrictamente político y económico, el Estado también produce tipos de relaciones sociales en el conjunto de la sociedad. Particularmente, a través de las funciones de redistribución con que 
orienta la actividad económica vinculada a su intervención sobre el manejo de los recursos.

Así como existe un sistema económico que la acción estatal propicia, atendiendo a las relaciones del país con el mundo - especialmente en América Latina, donde las economías son dependientes de los centros mundiales-, hay otro, de tipo social, que incide en el acceso y distribución de los recursos que la primera produce. Las políticas económicas y sociales, en tal sentido, son las principales herramientas. Sin embargo, se trata de un poder de intervención nunca neutro, tanto por los objetivos que persigue como por los grupos sociales a los que favorece o perjudica o por quiénes son los que deciden todo ello. Tal resultado es lo que marca el carácter social —o de clase- del Estado.

Pues bien, en el Chile que enfrenta la pandemia, las limitaciones en el actuar estatal durante la emergencia sanitaria abren un cuestionamiento a la arquitectura financiera vigente. En particular, a la autonomía de los Bancos Centrales que hoy ya es discutida en países de Europa y en los propios Estados Unidos ${ }^{10}$ a raíz del peligro de captura por intereses empresariales que entraña su autonomización del escrutinio público y ciudadano. De allí en más, ello significa la construcción de una regulación democrática no solo de tales entidades, sino, en general, de los mercados financieros, incluidos controles más estrictos a los créditos. En efecto, la crisis económica de 2008 fue eminentemente financiera y puso a la vista el descontrol de este sistema, involucrando caros salvatajes estatales. Esta vez, el sistema financiero es tensionado desde afuera por una crisis sanitaria, pero vuelve a ponerse a prueba.

En horas de incertidumbre, el poder de determinación de un Banco Central autónomo en Chile devela la inexistencia de un sistema robusto en el aparato de transferencia social del Estado cuya activación se produzca en función de objetivos sociales provenientes de la política y no de determinaciones económicas - a menudo abstractas- ajenas a ella. Y es que, hasta ahora, y más allá de la calidad de la gestión de los recursos entregados mediante los planes de contingencia, las fuentes desde las que se obtienen los mismos abren una serie de dudas. Por ejemplo, respecto de cuál es el límite de la deuda soberana en el Chile actual. En ese sentido, frente a la necesidad de procurar recursos al Estado para ampliar las ayudas estatales con que se enfrenta la pandemia, la elección de unas fuentes de financiamiento por sobre otras, especialmente en circunstancias en que las elegidas han utilizado la mediación empresarial, se torna un asunto opaco y extraño a la deliberación ciudadana. Así las cosas, las determinaciones de un ente que se rige con sus propias reglas y criterios, apelando a la calidad experta de sus integrantes, se impone ante un Ejecutivo que

10. Véase, por ejemplo, lo planteado por el periódico The Economist (2018). 
queda privado de tomar decisiones soberanas al respecto, pese a que sí fue elegido por decisión ciudadana.

Pero, además de las fuentes de financiamiento y de los grilletes no democráticos que condicionan la discusión, con un Banco Central y un ministerio de Hacienda que hasta ahora se niegan a tomar el camino de la deuda usando su discrecionalidad sobre tal decisión, se abre otro debate sobre cómo se distribuyen esos recursos. Y, frente a ello, vuelve a predominar una discrecionalidad que responde a una racionalidad privada y no pública, al delegarse el ejercicio de los planes de emergencia en instituciones financieras privadas. En realidad, además de conectar con el problema de la democracia, aquella apuesta realizada por el gobierno remite también a la cuestión del empobrecimiento del carácter público del Estado en Chile. La desnaturalización de lo público producto del avance de un capitalismo que crece al alero de la mercantilización de los servicios sociales subraya una privatización de la acción estatal a partir de una colonización empresarial que, incluso en la emergencia, le impide al Estado desapegarse del registro del subsidio a la ganancia privada. A partir de ello, las reglas de la ayuda estatal de emergencia las ponen los bancos, pese al marco general que provee el gobierno, pues ellos dirimen entre las MiPymes o indican la tasa de interés a la que los créditos con garantía estatal se prestan.

La apuesta del gobierno por evitar el conflicto con los grandes empresarios incluso en medio de la catástrofe indica la hondura de la amputación de las capacidades del Estado. En ello se cruzan desde ideologismos relacionados con la primacía del derecho de propiedad por sobre cualquier otro, como ocurre con la negativa a fijar leyes inmediatas - incluso en Estado de Excepción Constitucional de Catástrofe- para impedir los cortes de servicios básicos por deudas o controlar las alzas de precios de alimentos y otros productos, hasta el extremo de una especie de "filantropía con el Estado" como la exhibida en el caso de los ventiladores gestionados en China por la Confederación de la Producción y del Comercio, una operación sustentada en un fondo de recursos privados con el que se ha pretendido hacer olvidar la baja carga impositiva que enfrentan los más ricos en Chile.

La subsidiaridad extrema a la vista en esta crisis, propia del capitalismo de servicio público, no se reduce, por cierto, a la bancarización forzada que afecta a las MiPymes y que aquí se ha desarrollado. Por el contrario, también es visible en lo que respecta a la desesperada presión gubernamental para que las clínicas privadas colaboren frente a la pandemia. Efectivamente, ante el perjuicio de su rentabilidad económica, basada en la explotación privilegiada de ciertas áreas de atención por sobre otras dentro de su operación, varias de las más renombradas clínicas privadas han dilatado la recepción de pacientes derivados y el aumento de las camas UCI. Años de subsidios estatales a la salud privada, aunque han aumentado 
la infraestructura, no han creado un sistema de salud integrado, único medio para salvar vidas hoy, como lo ha reconocido el mundo entero, sino una serie de feudos y negocios aislados.

En suma, un Estado amputado de brazos para actuar ante crisis vitales como la del Coronavirus es un tema urgente que debe ser abordado. La institucionalidad social del Estado, que regula la relación entre sociedad y economía tanto "hacia abajo" - con la protección de los que más lo necesitan - como "hacia arriba" frente al apetito empresarial y rentista que apuesta por la concentración económica-, debe ser objeto de reforma. No basta, como devela la coyuntura, con enfocarse solo en aumentar las fuentes de ingresos, por ejemplo, a través de una reforma tributaria, por cierto, necesaria. También es relevante la democratización y transparencia de la institucionalidad estatal, tanto en su dimensión política como social. 


\section{REFERENCIAS}

ADN Radio (2020). "Presidente Asociación de Bancos: 'Los niveles de deterioro de cartera todavía están por verse"”. ADN Radio, 20 de mayo.

Alonso, C. (2020a). "Personas sin trabajar rondarán el 18\% y pobreza vuelve a ser una amenaza". La Tercera, 9 de mayo.

Alonso, C. (2020b). "Quiebra de personas sube 40\% en abril y totalizan casi dos mil casos en el año”. La Tercera, 11 de mayo.

Banco Central (2020a). Informe de Estabilidad Financiera, primer semestre 2020.

Banco Central (2020b). Informe de Cuentas Nacionales por Sector Institucional, Cuarto Trimestre 2019.

Cepal (2020). "El desafío social en tiempos del Covid-19". Informe especial Covid-19, Núm. 3, 12 de mayo.

Diario Financiero (2020a). "Garantía Corfo del fondo para firmas no bancarias será de US\$150 millones”. Diario Financiero, 19 de mayo.

Diario Financiero (2020b). "Boston Consulting Group anticipa contexto 'favorable' para oportunidades de M\&A tras reapertura económica”. Diario Financiero, 30 de abril.

El Mostrador (2020). “Cómo se 'peló el chancho' en las garantías estatales para los créditos Pyme Covid-19 (que aún no se otorgan)”. El Mostrador, 13 de mayo.

Faletto, E. (1989). "La especificidad del Estado en América Latina". Revista de la Cepal, Núm. 38, agosto.

Fazio, H. y Parada, M. (2010). Veinte años de política económica de la Concertación. Santiago de Chile: LOM Ediciones.

Ffrench-Davis, R. (2018). Reformas económicas en Chile, 1973-2017. Santiago de Chile: Taurus.

Financial Times (2020). "Virus lays bare the frailty of the social contract", editorial board, 3 de abril.

Fundación Nodo XXI (2020). "Reflexiones en tiempos de pandemia. Análisis de Coyuntura", Núm. 2, mayo.

INE (2020). Boletín estadístico: Empleo trimestral, Edición Núm. 259, 29 de mayo de 2020.

Leiva, M. (2020). "Decreto Fogape dispone que el 25\% del fondo debe ser para empresas de menor tamaño". La Tercera, 24 de abril. 
Ministerio de Economía (2019). Encuesta Longitudinal de Empresas, Núm. 5.

Ministerio de Hacienda (2020). Reglamento de administración del Fondo de Garantía para Pequeños y Medianos Empresarios aplicable a las líneas de garantía Covid-19. Santiago de Chile, 24 de abril.

Müller, E. (2020). "Alemania sale al rescate de Lufthansa con un paquete de ayudas de 9000 millones de euros.” El País, 25 de mayo.

Ocde (2020). “¿Cómo va la vida en Chile?”. > Oecd Better Life Initiative.

OIT (2020). COVID-19 and the world of work: Impact and policy responses, ILO Monitor $1^{\text {st }}$ Edition, 18 de marzo.

Ruiz, C. (2020). Octubre chileno. La irrupción de un nuevo pueblo. Santiago de Chile: Taurus.

Ruiz, C. (2019). La politica en el neoliberalismo. Experiencias latinoamericanas. Santiago de Chile: LOM Ediciones.

Ruiz, C. y Caviedes, S. (2020). "Estructura y conflicto social en la crisis del neoliberalismo avanzado chileno". Espacio abierto: Cuaderno Venezolano de Sociología, Vol. 29, Núm. 1, enero-marzo, pp. 86-101.

Solimano, A. (2012). Capitalismo a la chilena. Y la prosperidad de las élites. Santiago de Chile: Editorial Catalonia.

The Economist (2018). "A debate about central-bank independence is overdue", 18 de octubre.

Urquieta, C. (2020). "Asesores de la ministra del Trabajo explican por qué 'grandes empresas' pueden acogerse a la suspensión de remuneraciones”. Ciper, 26 de abril. 